\title{
Research priorities for non-pharmacological therapies for common musculoskeletal problems: nationally and internationally agreed recommendations
}

\author{
Nadine E Foster*1, Krysia S Dziedzic ${ }^{1}$, Danielle AWM van der Windt ${ }^{1,2}$, \\ Julie M Fritz ${ }^{3}$ and Elaine M Hay ${ }^{1}$
}

Address: ${ }^{1}$ Arthritis Research Campaign National Primary Care Centre, Keele University, Keele, Staffordshire, UK, ${ }^{2}$ Institute for Research into Extramural Medicine, VU University Medical Centre, Amsterdam, The Netherlands and ${ }^{3}$ Division of Physical Therapy, University of Utah, Salt Lake City, USA

Email: Nadine E Foster* - n.foster@keele.ac.uk; Krysia S Dziedzic - k.s.dziedzic@cphc.keele.ac.uk; Danielle AWM van der Windt - dawm.vanderwindt@vumc.nl; Julie M Fritz - julie.fritz@hsc.utah.edu; Elaine M Hay - e.m.hay@cphc.keele.ac.uk

* Corresponding author

Published: 9 January 2009

BMC Musculoskeletal Disorders 2009, 10:3 doi:10.1 186/147|-2474-10-3
Received: 18 July 2008

Accepted: 9 January 2009

This article is available from: http://www.biomedcentral.com/I47I-2474/I0/3

(c) 2009 Foster et al; licensee BioMed Central Ltd.

This is an Open Access article distributed under the terms of the Creative Commons Attribution License (http://creativecommons.org/licenses/by/2.0), which permits unrestricted use, distribution, and reproduction in any medium, provided the original work is properly cited.

\begin{abstract}
Background: Musculoskeletal problems such as low back pain, neck, knee and shoulder pain are leading causes of disability and activity limitation in adults and are most frequently managed within primary care. There is a clear trend towards large, high quality trials testing the effectiveness of common non-pharmacological interventions for these conditions showing, at best, small to moderate benefits. This paper summarises the main lessons learnt from recent trials of the effectiveness of nonpharmacological therapies for common musculoskeletal conditions in primary care and provides agreed research priorities for future clinical trials.

Methods: Consensus development using nominal group techniques through national (UK) and international workshops. During a national Clinical Trials Thinktank workshop in April 2007 in the UK, a group of 30 senior researchers experienced in clinical trials for musculoskeletal conditions and 2 patient representatives debated the possible explanations for the findings of recent high quality trials of non-pharmacological interventions. Using the qualitative method of nominal group technique, these experts developed and ranked a set of priorities for future research, guided by the evidence from recent trials of treatments for common musculoskeletal problems. The recommendations from the national workshop were presented and further ranked at an international symposium (hosted in Canada) in June 2007.

Results: 22 recommended research priorities were developed, of which 12 reached consensus as priorities for future research from the UK workshop. The 12 recommendations were reduced to 7 agreed priorities at the international symposium. These were: to increase the focus on implementation (research into practice); to develop national musculoskeletal research networks in which large trials can be sited and smaller trials supported; to use more innovative trial designs such as those based on stepped care and subgrouping for targeted treatment models; to routinely incorporate health economic analysis into future trials; to include more patient-centred outcome measures; to develop a core set of outcomes for new trials of interventions for musculoskeletal problems; and to focus on studies that advance methodological approaches for clinical trials in this field.

Conclusion: A set of research priorities for future trials of non-pharmacological therapies for common musculoskeletal conditions has been developed and agreed through national (UK) and international consensus processes. These priorities provide useful direction for researchers and research funders alike and impetus for improvement in the quality and methodology of clinical trials in this field.
\end{abstract}




\section{Background}

Musculoskeletal problems such as low back pain, neck, knee and shoulder pain are leading causes of disability and activity limitation in adults and are most frequently managed within primary care in the UK $[1,2]$. For example, non-specific low back pain has a one-month prevalence of $35-37 \%$ [3] and lifetime prevalence of between $49-70 \%$ [4], leading to large health care costs and loss of productivity [5]. Around one third of episodes of back pain result in persistent disabling symptoms [6] and this is similar across other musculoskeletal problems such as neck or shoulder pain [7] and knee pain $[1,8]$. In older people, the most frequent cause of pain and disability is joint pain. Recent estimates suggest up to 8.5 million people in the UK are affected by joint pain [9]. The primary prevention of these conditions has proven difficult, therefore management approaches focus on prevention of unnecessary limitations in activity and maximising participation.

Non-pharmacological therapies have a central role in the management of these common musculoskeletal conditions in primary care. Treatment options include advice and education, reassurance, help with self-management in terms of symptom control, coping strategies and prevention of further chronicity, in addition to individual exercise programmes and manual therapy. Clinical trials to date have shown some positive results for these interventions, but it is clear that they do not suit all patients [10]. The evaluation of these types of interventions has grown substantially over the last decade, evidenced by the increasing number of published randomised clinical trials [11] coupled with initiatives to try to improve their methodological quality [12]. Key features of high quality randomised clinical trials (RCTs) include recruitment of a sample representative of the patient group, randomisation of individuals, an appropriate control or comparison treatment (sometimes a placebo), concealment of the intervention from both patients and therapists, and an intention-to-treat analysis.

However, designing RCTs of non-pharmacological interventions that accurately reflect the complexities of clinical care is challenging. Complex interventions try to change the behaviour of patients or practitioners, for example, through adhering to healthcare advice or a home exercise programme [13]. Thus they depend on a range of factors, including the beliefs and behaviours of the health professional and the beliefs and adherence of the patient. Typically, non-pharmacological therapies are delivered as part of a package of care rather than as a single treatment alone [14], further complicating the design of trials to test treatment effectiveness. The methodological challenges posed by studying 'complex' interventions [13] include the need to define the various components of the intervention including their anticipated specific and non-specific effects, determine the characteristics of patients that may respond to a multi-modal intervention and ensure consistent and high quality delivery of the treatment programme.

In line with systematic reviews in this area [15-20], there is a clear trend towards large, high quality RCTs showing, at best, small to moderate benefits from non-pharmacological interventions for patients with musculoskeletal pain [e.g. [21,22]] and either no differences or very small differences between the effectiveness of different approaches [23,24]. Examples of pragmatic trials recently published include those from our research groups $[22,25-$ $28]$ and others [21,29-33]. In the field of low back pain alone, there have been several recent, high-quality trials showing only small differences in improvements of disability, of questionable clinical significance, between various types of non-pharmacological therapies, or between these and usual primary care $[21,25,29,32,34,35]$.

These 'negative' findings are strongly at odds with the experiences of health care practitioners who see individual patients improve, often dramatically, leading practitioners to believe in the effectiveness of specific interventions. These issues were the focus of an initiative to develop agreed priorities to guide the future research agenda for intervention studies in this field. The process involved a national Clinical Trials Thinktank workshop held in the UK and, subsequently, an international symposium held in Canada during the World Confederation of Physical Therapy congress in 2007. The aim was to provide an arena for discussion and to develop agreed recommendations for future studies testing the effectiveness of non-pharmacological interventions for common musculoskeletal pain. This paper provides an overview of the key explanations from the expert participants for the results of recent high quality clinical trials of non-pharmacological interventions, summarises the recommendations made by experts in this field and presents the agreed set of priorities for the future research agenda for the evaluation of non-pharmacological interventions for common musculoskeletal problems.

\section{Methods}

A set of agreed priorities for future research investigating the effectiveness of interventions for common musculoskeletal problems was developed through a process of consensus, in two stages reflecting national (UK) and international perspectives.

Stage 1 comprised the Clinical Trials Thinktank in the UK with national experts in clinical trials for common musculoskeletal conditions, held at the Arthritis Research Campaign National Primary Care Centre at Keele University. 
Over two days, 30 experienced UK-based clinical trialists from the fields of musculoskeletal pain and two patient representatives addressed a series of questions through discussion and debate. The professionals came from the following backgrounds: physiotherapy and related allied health disciplines including occupational therapy and podiatry, primary care including general practice, public health medicine, health services research, chiropractic, rheumatology, clinical trials methodology, biostatistics and health economics. Several participants were also involved in leading or contributing to the funding agendas of national research funding agencies. The questions were:

1. What have we learned from conducting high quality RCTs of non-pharmacological interventions for musculoskeletal pain presenting to primary care?

2. What recommendations can be made for future studies of non-pharmacological interventions?

\section{Which of these recommendations are agreed priorities?}

Invited delegates were either experienced researchers who had published clinical trials or protocols of clinical trials of non-pharmacological interventions for common musculoskeletal problems or patients representatives with musculoskeletal problems. During the workshop, participants presented brief summaries of example trials [2126,36-39], and participated in themed discussions specifically addressing each of the above questions. In each session, the questions were considered in light of the patient population, the interventions delivered and the outcomes measured. Following these discussions, participants developed a set of recommendations for the design and conduct of studies investigating the effectiveness of nonpharmacological interventions for musculoskeletal conditions using a nominal group technique (NGT). This is a group-based method through which information is gathered from experts in a structured way and consensus on a particular topic is facilitated [40]. Led by facilitators, workshop participants generated initial opinions and recommendations for future clinical trials, participants then contributed their suggestions to the group for discussion, these suggestions were clarified and tabulated and then participants independently ranked each recommendation according to their view of their relative importance. On a 5-point Likert scale ranging from 'Strongly Disagree' to 'Strongly Agree', participants ranked their agreement with each of the recommendations. These rankings were tabulated and presented back to the group for further discussion. For the purposes of prioritising those for which a high level of agreement was evident, the consensus level was set as those recommendations that received a median ranking of 4 or more and on which more than $75 \%$ of par- ticipants agreed or strongly agreed. NGT has been described as a 'hybrid' of the Delphi method and the focus group [41]. It was particularly suitable for this initiative since all participants in the group are given the opportunity to contribute ideas and all rankings are completed privately and independently, thus limiting the potential for participants to influence each other's recommendations. The output from the UK-based Thinktank workshop was therefore considered to be a list of nationally agreed recommendations to guide the future research agenda in this field.

In Stage 2, the recommendations from the UK Thinktank were taken to the largest international physical therapy congress in order to be further prioritised by colleagues from other countries. The recommendations were presented to an international forum, through a specific symposium, at the World Confederation of Physical Therapy in Vancouver, Canada in June 2007 http://www.wcpt.org where 133 participants considered the recommendations and prioritised them, again using a process of independent ranking using the same Likert scale described previously. The Confederation is a non-profit organisation comprising 92 member organisations which, together, represent more than 250,000 physical therapists worldwide. Twenty-four countries were represented among the 133 participants, mostly from North America and Western Europe, but also including South America, Asia and South Africa. More than half identified themselves as researchers $(\mathrm{n}=80,62.5 \%)$ with the others comprising practitioners, educators, managers and others. Following the ranking process at the international symposium, using the same criterion for consensus, the output was an internationally agreed set of priority recommendations.

\section{Results}

In Stage 1, 32 national (UK) experts participated in the UK Thinktank workshop over two days. The following provides a summary of key findings for each of the three questions addressed within the workshop.

\section{What have we learned from conducting high quality RCTs of non-pharmacological interventions for musculoskeletal pain in primary care?}

From the selection of example trials presented, several observations were made and discussed at length within the workshop. Firstly, when common non-pharmacological interventions were compared with other primary care interventions, such as care from general practitioners (GP), then trials generally showed significant differences between groups. For example, a pragmatic RCT by Hay and colleagues [22] compared usual primary care with community physiotherapy for older adults with chronic knee pain, and showed short-term benefits of physiotherapy over usual GP care. Secondly, when two or more dif- 
ferent non-pharmacological interventions in primary care were compared, then trials appeared most likely to show no significant differences between groups. For example, no difference between two or more physiotherapy approaches for low back pain patients $[23,25,29]$ or neck pain patients [26]. Thirdly, when the primary outcome data were plotted on a graph over time, the similarity of findings, in terms of changes in pain and function, across trials of low back pain, neck pain, knee pain and shoulder pain was striking, irrespective of the specific interventions being tested.

Several explanations for the trends in the findings of recent trials were discussed. Given the similarity in trial findings, one key explanation was that non-pharmacological interventions in primary care provide little benefit for patients with musculoskeletal conditions and do not change the natural course of these conditions over time. Patient selection was discussed in relation to the problem of heterogeneity of the samples within previous trials, such that the average treatment effect masks a wide range of individual responses to treatment, including for example patients who benefit a great deal along with those who benefit little or not at all. Participants suggested there has been inadequate identification of important patient subgroups in previous trials. Discussion highlighted that previous trials had been based on a traditional, but perhaps unrealistic, expectation of moderate to large effects of non-pharmacological, primary care-based interventions for patients with common musculoskeletal patients. In fact, the overall message from previous trials is one of small and often short-term effects, some of which may be clinically meaningful whilst others may not. If the results of multiple high quality clinical trials give the 'true' picture for the majority of patients, then dramatic improvements seen in individual patients are not representative of the impact of non-pharmacological therapies in general for populations with musculoskeletal conditions. Powering clinical trials to compare different interventions to show anything other than small differences between groups appeared particularly unrealistic.

Participants debated the likelihood that previous clinical trials' investigators had overestimated the specific treatment effects of interventions and underestimated the non-specific treatment effects, such as the attention, support and empathy provided by a health care practitioner and individual patients' and practitioners' preferences and expectations. This was felt to help explain the lack of significant differences between interventions seen in previous trials. A further explanation was, that despite many trials now incorporating recommended and validated outcome measures, these may still be failing to capture what is really important to patients. There was a general view that there continues to be inadequate measurement of outcomes that are important to patients, in terms of both the timing of outcome assessments and the constructs being captured by available validated outcome measures, such as pain-related disability. A final explanation debated to what degree the interventions within previous trials were effectively applied, with some participants of the view that there has been insufficient attention to the assessment of skills and competencies of clinicians providing the interventions and their adherence to the intervention protocols stipulated by the trial procedures. Following these discussions, participants generated their recommendations for future studies.

\section{What recommendations can be made for future studies of non-pharmacological interventions?}

As a result of the independent suggestions from participants, a list of 22 recommendations was generated, presented in Table 1. Following clarification and discussion, these were then subjected to independent ranking.

\section{Which of these recommendations are agreed priorities?} From the original set of 22 recommendations, an agreed list of 12 priorities was generated as a result of the independent ranking, highlighted in Table 1 . The 12 recommendations were ranked, again independently, at the WCPT international symposium with 133 participants from 24 different countries. Of the 12 recommendations, 7 reached our agreed level of consensus and are highlighted in Table 1. Those describing themselves as researchers and those describing themselves as practitioners selected the same top 7 recommendations in their ranking exercise. There was clear agreement on the need for future research to focus further on implementation (research into practice) for musculoskeletal conditions, the potential benefit of developing national musculoskeletal research networks through which support for trials could be provided, to develop more innovative trial designs such as those based on stepped care and subgrouping for targeted treatment approaches and for health economic analysis to become a common component of future clinical trials. In addition, the recommendations to include more patient-centred outcomes in trials, to develop a core set of outcomes for new trials to allow comparisons in the future and to conduct studies that advance methodological approaches for clinical trials also met our consensus criteria. The implications of these priority recommendations are discussed below.

\section{Discussion}

Through two focused workshops, this initiative has developed a set of priorities that can guide future research testing the effectiveness of non-pharmacological, primary care-based interventions for common musculoskeletal conditions. The recommendations aim to encourage high quality and innovative clinical trials that can answer the 
Table I: Summary of recommendations for future trials of non-pharmacological interventions for musculoskeletal problems

\begin{tabular}{|c|c|c|c|c|}
\hline & Recommendation & $\begin{array}{l}\text { Reached consensus in } \\
\text { UK Clinical Trials } \\
\text { Thinktank }\end{array}$ & $\begin{array}{l}\text { Reached consensus in } \\
\text { International } \\
\text { Symposium }\end{array}$ & $\begin{array}{l}\text { Level of } \\
\text { agreement }(\% \\
\text { agreement) } *\end{array}$ \\
\hline I & $\begin{array}{l}\text { Focus on implementation (research into practice) for } \\
\text { musculoskeletal conditions }\end{array}$ & $*$ & $*$ & $90.1 \%$ \\
\hline 2 & $\begin{array}{l}\text { Develop national musculoskeletal research networks in } \\
\text { which large trials can be sited and smaller trials supported }\end{array}$ & * & * & $87.9 \%$ \\
\hline 3 & $\begin{array}{l}\text { Develop more innovative trial designs (such as those } \\
\text { based on stepped care, subgrouping patients and targeting } \\
\text { treatment) }\end{array}$ & * & $*$ & $83.2 \%$ \\
\hline 4 & Include more patient-individualised outcomes & $*$ & $*$ & $83.9 \%$ \\
\hline 5 & $\begin{array}{l}\text { Develop core sets of outcomes for new trials to allow } \\
\text { comparisons across trials }\end{array}$ & $*$ & $*$ & $81.2 \%$ \\
\hline 6 & Include cost-effectiveness analysis within clinical trials & $*$ & $*$ & $77.3 \%$ \\
\hline 7 & Focus on studies that advance clinical trials methodology & $*$ & $*$ & $77.1 \%$ \\
\hline 8 & $\begin{array}{l}\text { Compare non-pharmacological interventions to 'real life' } \\
\text { controls } \\
\text { (groups receiving no treatment or usual primary care) }\end{array}$ & $*$ & & $77.4 \%$ \\
\hline 9 & $\begin{array}{l}\text { Investigate the specific versus non-specific effects of } \\
\text { treatments to determine what it is about the } \\
\text { interventions that is effective }\end{array}$ & * & & $73.8 \%$ \\
\hline 10 & $\begin{array}{l}\text { Develop intervention models that match the natural } \\
\text { history of common musculoskeletal problems (long-term } \\
\text { conditions require long-term model of care such as that } \\
\text { used in diabetes or asthma) }\end{array}$ & $*$ & & $69.9 \%$ \\
\hline II & Conduct pilot studies to develop innovative trial designs & $*$ & & $68.2 \%$ \\
\hline 12 & $\begin{array}{l}\text { Capture the effects of treatment earlier } \\
\text { (eg. weeks not months) }\end{array}$ & * & & $65.4 \%$ \\
\hline 13 & $\begin{array}{l}\text { Distinguish first the natural history of conditions and then } \\
\text { look at effects of interventions }\end{array}$ & & & - \\
\hline 14 & $\begin{array}{l}\text { Test treatments that are already in practice within future } \\
\text { trials }\end{array}$ & & & - \\
\hline 15 & $\begin{array}{l}\text { Focus more on phase I and } 2 \text { studies (modelling and } \\
\text { piloting) before proceeding to clinical trials }\end{array}$ & & & - \\
\hline 16 & $\begin{array}{l}\text { Focus on earlier timing of interventions in the history of } \\
\text { the musculoskeletal problem }\end{array}$ & & & - \\
\hline 17 & $\begin{array}{l}\text { Use new trial designs but use them to answer specific } \\
\text { research questions more efficiently }\end{array}$ & & & - \\
\hline 18 & $\begin{array}{l}\text { Go back to some of the key basics within trials and } \\
\text { improve the measurement of process issues, improve } \\
\text { outcomes and ensure quality of treatment }\end{array}$ & & & - \\
\hline 19 & $\begin{array}{l}\text { Explore how to engage private providers of care in } \\
\text { research and clinical trials in more optimal ways }\end{array}$ & & & - \\
\hline 20 & $\begin{array}{l}\text { Use equivalence and non-inferiority trials rather than the } \\
\text { traditional superiority trial design, when appropriate }\end{array}$ & & & - \\
\hline 21 & $\begin{array}{l}\text { Develop 'mega-trials' } \\
\text { (national and multi-national clinical trials) }\end{array}$ & & & - \\
\hline 22 & Make better use of data from previous trials & & & - \\
\hline
\end{tabular}

* Percentage agreement (agreed or strongly agreed) by 133 participants of International Symposium

questions that are important to primary care clinicians and their musculoskeletal pain patients. It is important to stress that the key feature of our approach in this study is the consensus of experts, including patients, in the field of trials of non-pharmacological primary care-based interventions for musculoskeletal conditions. It was not our intention to present the priorities as the sole priorities for research in this field, but to bring experts together to generate and agree a set of priorities for interventions studies that could be published and used to influence future research and funding strategies.

\section{Agreed priority - Focus on implementation}

The desire to implement research findings into practice has increased in priority with the amount of evidence now generated in the musculoskeletal pain literature. Simultaneously there has been an acknowledgement that the evidence alone cannot be implemented without facilitation 
[42-45]. However optimal methods for achieving this are still uncertain. Development of clinical guidelines has been one mechanism for enhancing uptake of research into practice [46]. For example, exercise is recommended as a core treatment by the National Institute of Health and Clinical Excellence in the UK in their recent osteoarthritis guidelines [47] as a result of evidence from high quality RCTs of non-pharmacological interventions [e.g. $[22,28,36,48]]$. Unfortunately implementation strategies for clinical guidelines are complex and studies in this field are challenging. It is not surprising therefore that this recommendation was highly rated by both national and international participants in this consensus study.

\section{Agreed priority - Develop national Musculoskeletal Research Networks}

This priority is timely, and reflects a growing commitment of the research community to adopt a collaborative, rather than competitive, approach to clinical research. It is increasingly unrealistic for lone researchers, working in isolation, to produce high quality RCTs and other clinical studies required to answer important research questions. As an example of the increasing recognition of this, in October 2007 the Arthritis Research Campaign (arc), the fourth largest medical charity in the UK and the only one solely dedicated to research in musculoskeletal conditions, launched a new initiative. They formed seven Clinical Studies Groups, to support clinical trials and related research within the UK [49]. In partnership with the UK Comprehensive Research Network, the Clinical Studies Groups will develop nationally agreed strategic plans for clinical research in arthritis and related musculoskeletal conditions. This initiative aims to be inclusive, with the expressed aim of encouraging and facilitating clinician engagement in research in a variety of ways; for example by helping develop research questions, by developing and delivering novel interventions, through to being Principal Investigators on named projects. Full details of the arc Clinical Studies Groups can be found on http:// www.arc.org.uk but this provides one key example of how this recommendation can be taken forward at a national level.

\section{Agreed priorities - Develop more innovative trial designs and studies that advance methodological approaches}

Ideally, strictly designed RCTs are carried out among homogeneous groups of patients, in order to limit individual variation and optimize prognostic similarity of intervention groups. The drawback of this is the limited generalisability of findings. In recent years there has been a shift towards pragmatic RCTs, in which more heterogeneous patients group are recruited. In these trials the reported average effect of treatment may obscure a wide variation in individual responses, with some patients showing dramatic improvement while others hardly respond to the same intervention [50]. One solution may be to offer more complex or more intensive interventions only to those patients who do not respond to initial treatment. The effectiveness of such a stepped care approach is currently being evaluated in a trial with patients with whiplash-related disorders [38]. Treatment effectiveness may also be improved by closer matching of treatments to individual patients' characteristics. Secondary analyses of a trial with back pain patients comparing a psychosocial intervention to usual primary care showed that profiles of patients responding favorably to treatment differed between intervention groups even though the effects measured at group level showed no difference at all [50]. The main challenge is how to select or subgroup patients that may benefit more from specific (or targeted) interventions. Prediction rules have been designed to identify patients responding particularly well to some non-pharmacological interventions [51,52] and a communitybased intervention has been developed to identify and target psychosocial risks in individual patients [53]. Further research is needed to establish whether the use of prediction rules (prognostic stratification) indeed leads to better patient outcomes and more efficient care [39]. As such trials address complex interventions and have more sophisticated designs, they require large sample sizes. They also tend to require several phases of developmental work, for example as described by the MRC framework for the development and evaluation of complex interventions $[54,55]$.

\section{Agreed priority - Health economic and cost-effectiveness analysis}

The economic burden of musculoskeletal conditions has been well documented [56]. For low back pain in the United States alone these costs are over $\$ 100$ billion per year [57] and much of these costs result from prolonged care for those patients who fail to recover and progress to chronic disability. An important goal of primary care interventions is thus to reduce the likelihood of, and costs associated with, chronicity and ongoing management [58]. Including health economic alongside clinical outcomes in RCTs is needed to be able to fully evaluate interventions. This is particularly important when the differences in clinical outcomes between treatments are small. Cost-effectiveness analysis, which compares the relative clinical benefits of different treatments to their relative costs, can identify treatments that provide the best value. For example, a recent trial found no significant differences in clinical outcomes between two non-pharmacologic interventions for patients with low back or neck pain; an approach based on cognitive-behavioural principles versus one based on the McKenzie approach to mechanical diagnosis and therapy [59]. The economic analysis included the clinical outcomes, the relative costs of each approach and of additional health care services, 
medication, lost wages and work productivity, and suggested the McKenzie approach was preferable [60]. Thus including health economic analysis is an important priority for future research to assist policy makers and patients in making decisions about interventions.

\section{Agreed priorities - Outcome measures}

The need to develop robust patient-based outcome measures and core sets of these for use within RCTs has been previously recognised as important within the general clinical trial literature [61] and within the musculoskeletal pain community. For example, the OMERACT initiative http://www.omeract.org/, an informal international network of health professionals that organizes meetings focused on outcome measurement across RCTs and observational studies [62] recognised the need for patients to actively participate in this activity. There are now excellent opportunities to use such core outcome sets within RCTs with musculoskeletal pain patients. In collaboration with OMERACT, disease specific outcome measures for RCTs have been recommended [e.g. $[63,64]]$. In the area of low back pain, an international group of researchers considered recommendations for standardised outcome measurement in clinical trials [65], whilst others have evaluated a core set of outcomes for whiplash-related disorders [66]. Not every musculoskeletal condition is covered but, increasingly, consensus on the important core domains is being reached. The development and use of patient-individualised measures are relatively rare but of increasing interest, as they allow the respondent to select issues or domains that are of personal concern rather than those which are solely predetermined by the investigator's list of questionnaire items [61]. Some such patient-individualised measures are available [e.g. [67]] and the suitability of using traditional outcomes alone for musculoskeletal pain patients questioned [68]. Alongside broadening the specific choice of outcomes is the possibility of revisiting the timing of outcome measurements in RCTs for common musculoskeletal conditions and considering the trajectory of the pain condition over time as an outcome rather than focusing on specified follow-up time points alone.

\section{Strengths and limitations}

We consider key strengths of this consensus initiative to include the independent generation of recommendations for future research, their independent ranking by both national and international researchers, clinicians and user representatives and the level of consensus reached by the top seven priorities. Participation in the workshops was excellent, from a wide range of disciplines, an indication of the relative importance placed on this topic by the community of researchers. Overall, participants wanted to acknowledge the positive progress made over recent years, in providing many high quality RCTs of non-pharmacological interventions for musculoskeletal conditions. There are now more clinical trialists within disciplines such as physiotherapy, occupational therapy and podiatry, than ever before, who aim to provide patients, practitioners and health policy makers with reliable evidence about nonpharmacological therapies. The workshops provided opportunity for discussion, debate and sharing of ideas and there was a great deal of enthusiasm for future similar opportunities. Potential weaknesses, as with all efforts to generate consensus, are that different participants may have provided different recommendations or prioritised the recommendations differently. Inevitably the results of priority-setting initiatives are dependent on the composition of the group of participants and further consensus-based initiatives in other countries and with other clinical disciplines would be useful. In addition, our focus was specifically on recommendations for future studies testing the effectiveness of non-pharmacological interventions for common musculoskeletal pain. Clearly, other types of research are also needed, such as research that provides better understanding of aetiological factors and mechanisms of action of interventions.

\section{Implications}

As a whole, this study should be considered as a step towards improved quality and innovation in future intervention studies, testing the effectiveness of non-pharmacological, primary-case based treatment options for musculoskeletal pain. The lessons learnt from previous trials, and the priorities identified can guide the development of further work of those involved in designing RCTs within the field of musculoskeletal care. The value of the agreed priorities will ultimately be in their use, for example, in justifying the case for funding of new studies, in their uptake by funding agencies as part of their commissioning processes and strategic plans, in the incorporation of these recommendations within new RCTs of non-pharmacological therapies, and in an increase in translational research studies that improve research into practice for patients with musculoskeletal conditions [69]. We hope these recommendations will be incorporated within new clinical trial proposals, help to develop future research collaborations to ensure standardisation of outcome measures that can facilitate future meta-analyses and secondary outcome syntheses, lead to an increase in the use of more innovative trial designs and encourage the publishing of clinical trial protocols in this field. We welcome suggestions of other national and international dissemination mechanisms for these research priorities, such as the involvement of relevant professional bodies, clinical interest groups and funding agencies.

\section{Conclusion}

Using a consensus approach, we have developed a set of priorities for the future research agenda, to guide studies testing the effectiveness of non-pharmacological interventions for patients with musculoskeletal pain. From 22 rec- 
ommendations, 12 were prioritised nationally and 7 internationally. These priorities have the potential to improve future clinical trials and therefore to provide more informative guidance to patients and practitioners. Widespread dissemination of these agreed priorities will optimise their usefulness.

\section{Competing interests}

The authors declare that they have no competing interests.

\section{Authors' contributions}

NEF, KSD, DvdW and EMH conceived the idea of holding a national Clinical Trials Thinktank in the UK and led these workshop discussions. NEF, KSD, JMF and DAWN VDW led the Focused Symposium at the WCPT Congress in Canada. All authors were involved in the design and data acquisition, analysis and interpretation of data. All authors were involved in drafting of the manuscript, revising it and providing final approval of the version to be published.

\section{Acknowledgements}

We would like to thank all the Clinical Trials Thinktank participants (Ms Roberta Ainsworth (physiotherapist and clinical trialist), Dr Majid Artus (general practitioner and researcher), Dr lain Beith (physiotherapist and clinical trialist), Ms Annette Bishop (physiotherapist and researcher), Prof Alan Breen (chiropractor and researcher), Dr Mindy Cairns (physiotherapist and clinical trialist), Mr Dickon Crawshaw (physiotherapist and clinical trialist), Dr Duncan Critchley (physiotherapist and clinical trialist), Dr Alison Hammond (occupational therapist and clinical trialist), Dr Jonathan Hill (physiotherapist and clinical trialist), Ms Mel Holden (physiotherapist and researcher), Prof Mike Hurley (physiotherapist and clinical trialist), Prof Tracy Howe (physiotherapist and researcher), Dr Kika Konstantinou (spinal specialist physiotherapist and researcher), Mrs Adele Higginbottom (patient representative), Mr Peter Hayes (patient representative), Prof Sallie Lamb (physiotherapist and clinical trialist), Dr Jeremy Lewis (physiotherapist and clinical trialist), Dr Martyn Lewis (biostatistician and health economics), Dr Chris McCarthy (physiotherapist and clinical trialist), Prof Suzanne McDonough (physiotherapist and clinical trialist), Dr Ricky Mullis (physiotherapist and clinical trialist), Prof Chris Salisbury (general practitioner and clinical trialist), Prof Alan Silman (rheumatologist and medical director of a UK funding agency), Prof Julius Sim (physiotherapist and clinical trialist), Prof David Torgerson (health services research, public health medicine and health economics), Prof Martin Underwood (general practitioner and clinical trialist) and Prof Jim Woodburn (podiatrist and clinical trialist)) and the WCPT symposium participants.

Nadine Foster is funded through a Primary Care Career Scientist Award from the National Institute of Health Research (NIHR), UK. Thanks are extended to the Chartered Society of Physiotherapy and British Health Professionals in Rheumatology for funding attendance at the WCPT 2007 congress. We would like to acknowledge the Arthritis Research Campaign National Primary Care Centre and North Staffordshire Primary Care Research Consortium for hosting the Thinktank in the UK.

\section{References}

I. Thomas E, Peat G, Harris L, Wilkie R, Croft PR: The prevalence of pain and pain interference in a general population of older adults: cross-sectional findings from the North Staffordshire Osteoarthritis Project (NorStOP). Pain 2004, I I 0:36I-8.
2. Woolf A, Akesson K: Understanding the burden of musculoskeletal conditions: the burden is huge and not reflected in national health priorities. BMJ 200I, 322:1079-80.

3. Papageorgiou AC, Croft PR, Ferry S, Jayson MIV, Silman AJ: Estimating the prevalence of low back pain in the general population. Evidence from the South Manchester Back Pain Survey. Spine 1995, 20:1889-94.

4. Van Tulder MW, Koes BW, Bombardier C: Low back pain. Best Practice and Research Clinical Rheumatology 2002, 16:761-75.

5. Maniadakis N, Gray A: The economic burden of back pain in the UK. Pain 2000, 84:95-103.

6. Thomas E, Silman AJ, Croft PR, Papageorgiou AC, Jayson MI, Macfarlane GJ: Predicting who develops chronic low back pain in primary care: a prospective study. BMJ 1999, 3 18:1662-67.

7. Bot Sd, Waal JM van der, Terwee CB, Windt DA van der, Schellevis FG, Bouter LM, Dekker J: Incidence and prevalence of complaints of the neck and upper extremity in general practice. Ann Rheum Dis 2005, 6 I(I): I I8-23.

8. Waal JM Van der, Bot SD, Terwee CB, Windt DA van der, Scholten RJ, Bouter LM, Dekker J: Course and prognosis of knee complaints in general practice. Arthritis Rheum 2005, 53(6):920-30.

9. Arthritis and Musculoskeletal Alliance. Standards of Care for people with osteoarthritis 2004 [http://www.arma.uk.net/].

10. Leboeuf-Yde C, Manniche C: Commentary. Low back pain: Time to get off the treadmill. JMPT 200I, 24(I):63-6.

II. Koes BW, Malmivaara A, van Tulder MW: Trend in methodological quality of randomised clinical trials in low back pain. Best Practice and Research Clinical Rheumatology 2005, 19(4):529-539.

12. Moher D, Schulz KF, Altman D: The CONSORT Statement: revised recommendations for improving the quality of reports of parallel-group randomised trials. JAMA 200I, 285: |987-9|.

13. Medical Research Council: A framework for development and evaluation of RCTs for complex interventions to improve health. London MRC; 1999.

14. Dieppe P: Short report: Complex interventions. Musculoskeletal Care 2004, 2(3): 180-6.

15. Fransen M, McConnell S, Bell M: Exercise for osteoarthritis of the hip or knee. The Cochrane Database of Systematic Reviews 2001:CD004376.

16. Green S, Buchbinder R, Hetrick S: Physiotherapy interventions for shoulder pain. Cochrane Database of Systematic Reviews 2003:CD004258.

17. Gross AR, Hoving JL, Haines TA, Goldsmith CH, Kay T, Aker P, Bronfort G: Cervical overview group. Manipulation and mobilisation for mechanical neck disorders. Cochrane Database Syst Rev 2004:CD004249.

18. Verhagen AP, Scholten-Peeters GGM, de Bie RA, Bierma-Zeinstra SMA: Conservative treatments for whiplash. The Cochrane Database of Systematic Reviews 2004:CD003338.

19. Hayden JA, van Tulder M, Malmivaara AV, Koes BW: Meta-analysis: exercise therapy for non-specific low back pain. Ann Intern Med 2005, 142:765-775.

20. Kroeling P, Gross A, Goldsmith CH, Cervical Overview Group: Electrotherapy for neck disorders. The Cochrane Database of Systematic Reviews 2005:CD00425I.

21. UK BEAM trial team: United Kingdom back pain exercise and manipulation (UK BEAM) randomised trial: effectiveness of physical treatments for back pain in primary care. BMJ 2004, 329:1377-80.

22. Hay EM, Foster NE, Thomas E, Peat G, Phelan M, Yates HE, Blenkinsopp $A, \operatorname{Sim~J:~Effectiveness~of~community~physiotherapy~and~}$ enhanced pharmacy review for knee pain in people aged over 55 presenting to primary care: pragmatic randomised trial. BMJ 2006, 333(7576):995.

23. Cairns MC, Foster NE, Wright C: Randomised controlled trial of specific spinal stabilisation exercises and conventional physiotherapy for recurrent low back pain. Spine 2006, 31 (19): E670-8I.

24. Hurley DA, McDonough SM, Dempster M, Moore AP, Baxter GD: A randomised clinical trial of manipulative therapy and inferential therapy for acute low back pain. Spine 2004, 29(20):2207-16.

25. Hay EM, Mullis R, Lewis M, Vohora K, Main CJ, Watson P, Dziedzic KS, Sim J, Minns Lowe C, Croft P: Comparison of physical treatments versus a brief pain management programme for back 
pain in primary care: a randomised clinical trial in physiotherapy practice. Lancet 2005, 365:2024-30.

26. Dziedzic K, Hill J, Lewis M, Sim J, Daniels J, Hay EM: Effectiveness of manual therapy or pulsed shortwave diathermy in addition to advice and exercise for neck disorders: a pragmatic randomised controlled trial in physical therapy clinics. Arthritis Rheum 2005, 53(2):2/4-22.

27. Heymans MW, de Vet HC, Bongers PM, Knol DL, Koes BW, van Mechelen $W$ : The effectiveness of high-intensity versus lowintensity back schools in an occupational setting: a pragmatic randomized controlled trial. Spine 2006, 31 I:1075-82.

28. Foster NE, Thomas E, Barlas P, Hill JC, Young J, Mason E, Hay EM: Acupuncture as an adjunct to exercise based physiotherapy for osteoarthritis of the knee: randomised controlled trial. BMJ 2007, 335(76I7):436.

29. Frost H, Lamb SE, Doll HA, Carver PT, Stewart-Brown S: Randomised controlled trial of physiotherapy compared with advice for low back pain. BMJ 2004, 329(7468):708.

30. Klaber Moffett JA, Jackson DA, Richmond S, Hahn S, Coulton S, Farrin A, Manca A, Torgerson DJ: Randomised trial of a brief physiotherapy intervention compared with usual physiotherapy for neck pain patients: outcomes and patients' preference. $B M]$ 2005, 330(7482):75.

31. Scholten-Peeters GG, Neeleman-van der Steen CW, Windt DA van der, Hendriks EJ, Verhagen AP, Oostendorp RA: Education by general practitioners or education and exercises by physiotherapists for patients with whiplash-associated disorders? A randomized clinical trial. Spine 2006, 3 I(7):723-3I.

32. Hancock MJ, Maher CG, Latimer J, McLachlan AJ, Cooper CW, Day $\mathrm{RO}$, Spindler MF, McAuley JH: Assessment of diclofenac or spinal manipulative therapy, or both, in addition to recommended first-line treatment for acute low back pain: a randomised controlled trial. Lancet 2007, 370(9599):1638-43.

33. Luijsterburg PA, Verhagen AP, Ostelo RW, Hoogen HJ van den, Peul WC, Avezaat CJ, Koes BW: Physical therapy plus general practitioners' care versus general practitioners' care alone for sciatica: a randomised clinical trial with a 12 -month followup. Eur Spine J 2008, I 7(4):509- 17

34. Carr JL, Klaber-Moffett JA, Howarth E, Richmond SJ, Torgerson DJ, Jackson DA, Metcalfe CJ: A randomised trial comparing a group exercise programme for back pain patients with individual physiotherapy in a severely deprived area. Disabil Rehabil 2005, 27:929-37.

35. Critchley DJ, Ratcliffe J, Noonan S, Jones RH, Hurley MV: Effectiveness and cost-effectiveness of three types of physiotherapy used to reduce chronic low back pain disability: a pragmatic randomized trial with economic evaluation. Spine 2007, 32(I4): |474-8I.

36. McCarthy CJ, Mills PM, Pullen R, Richardson G, Hawkins N, Roberts CR, Silman AJ, Oldham JA: Supplementation of a home-based exercise programme with a class-based programme for people with osteoarthritis of the knees: a randomised controlled trial and health economic analysis. Health Technol Assess 2004, 8(46): iii-iv. $|-6|$

37. Lewis JS, Hewitt JS, Billington L, Cole S, Byng J, Karayiannis S: A randomised clinical trial comparing two physiotherapy interventions for chronic low back pain. Spine 2005, 30(7):7II-2I.

38. Lamb SE, Gates S, Underwood MR, Cooke MW, Ashby D, Szczepura A, Williams MA, Williamson EM, Withers E], Isa S, Gumber A: Managing Injuries of the Neck Trial (MINT): design of a randomised controlled trial of treatments for whiplash associated disorders. BMC Musculoskeletal Disord 2007, 8:7.

39. Hill JC, Dunn KM, Lewis M, Mullis R, Main CJ, Foster NE, Hay EM: The STarT Back screening tool: subgroups for initial treatment of back pain in primary care. Arthritis Care and Research 2008, 59(5):632-4I

40. Jones J, Hunter D: Using the Delphi and nominal group technique in health services research. In $B M J$ Volume $3 / I$. 2nd edition. Issue 700I Edited by: Pope C, Mays N. London, BMJ Books; 1995:376-380.

41. Sim J, Wright C: Chapter 6 Designing a descriptive study. In Research in Health Care: Concepts, Designs and Methods Cheltenham, UK, Stanley Thornes Ltd; 2000:79.

42. Eccles M, Grimshaw J, Walker A, Johnston M, Pitts N: Changing the behavior of healthcare professionals: the use of theory in promoting the uptake of research findings. I Clin Epidemiol 2005, 58(2): $107-12$.

43. Kitson A, Harvey G, McCormack B: Enabling the implementation of evidence based practice: a conceptual framework. Qual Health Care 1998, 7(3): 149-58.

44. Michie S, Johnston M, Abraham C, Lawton R, Parker D, Walker A, "Psychological Theory" Group: Making psychological theory useful for implementing evidence based practice: a consensus approach. Qual Saf Health Care 2005, I4(I):26-33

45. Scott $\mathrm{I}$ : The evolving science of translating research evidence into clinical practice. Evid Based Med 2007, I 2(1):4-7.

46. Brand C, Cox S: Systems for implementing best practice for a chronic disease: management of osteoarthritis of the hip and knee. Intern Med J 2006, 36(3): I70-9.

47. National Institute of Clinical Excellence: The care and management of osteoarthritis in adults 2008 [http://www.nice.org.uk/cg059].

48. Hurley MV, Walsh NE, Mitchell HL, Pimm T], Patel A, Williamson E, Jones RH, Dieppe PA, Reeves BC: Clinical effectiveness of a rehabilitation program integrating exercise, self-management, and active coping strategies for chronic knee pain: a cluster randomized trial. Arthritis Rheum 2007, 57(7):12।I-9.

49. Silman A: A new paradigm for musculoskeletal clinical trials in the UK: the Arthritis Research Campaign (ARC) Clinical Studies Groups initiative. Rheumatology (Oxford) 2008, 47(6):777-9.

50. Jellema $P$, Horst HE van der, Vlaeyen JW, Stalman WAB, Bouter LM, Windt DAWM Van der: Predictors of outcome in patients with (sub)acute low back pain differ across treatment groups. Spine 2006, $31: 1699-705$.

5I. Flynn T, Fritz J, Whitman J, Wainner R, Magel J, Rendeiro D, Butler B, Garber M, Allison S: A clinical prediction rule for classifying patients with low back pain who demonstrate short-term improvement with spinal manipulation. Spine 2002, 27(24):2835-43.

52. Hicks GE, Fritz JM, Delitto A, McGill SM: Preliminary development of a clinical prediction rule for determining which patients with low back pain will respond to a stabilization exercise program. Arch Phys Med Rehabil 2005, 86: 1753-62.

53. Sullivan MJ, Stanish WD: Psychologically based occupational rehabilitation: the Pain-Disability Prevention Program. Clin J Pain 2003, 19:97-104.

54. Campbell M, Fitzpatrick R, Haines A, Kinmonth AL, Sandercock $P$ Spiegelhalter D, Tyrer P: Framework for design and evaluation of complex interventions to improve health. BMJ 2000, 321:694-6.

55. Campbell NC, Murray E, Darbyshire J, Emery J, Farmer A, Griffiths F, Guthrie B, Lester H, Wilson P, Kinmonth AL: Designing and evaluating complex interventions to improve health. BM] 2007, 334:455-459.

56. WHO Scientific Group: The Burden of Musculoskeletal Conditions at the Start of the New Millennium 2003 [http://whqlibdoc.who.int/trs/ WHO TRS 919.pdf].

57. Katz JN: Lumbar disc disorders and low-back pain: socioeconomic factors and consequences. J Bone Joint Surg 2006, 88(Suppl):2l-4.

58. Krismer M, van Tulder M: The Low Back Pain Group of the Bone and Joint Health Strategies for Europe Project. Strategies for prevention and management of musculoskeletal conditions. Low back pain (non-specific). Best Pract Res Clin Rheumatol 2007, $21: 77-91$.

59. Moffett JK, Jackson DA, Gardiner ED, Torgerson DJ, Coulton S, Eaton S, Mooney MP, Pickering C, Green AJ, Walker LG, May S, Young S: Randomized trial of two physiotherapy interventions for primary care neck and back pain patients: 'McKenzie' vs brief physiotherapy pain management. Rheumatology (Oxford) 2006, 45(I2):|15|4-2|.

60. Manca A, Dumville JC, Torgerson DJ, Klaber Moffett JA, Mooney MP, Jackson DA, Eaton S: Randomized trial of two physiotherapy interventions for primary care back and neck pain patients: cost effectiveness analysis. Rheumatol 2007, 46: I 495-50I.

6I. Fitzpatrick R, Davey C, Buxton MJ, Jones DR: Evaluating patientbased outcome measures for use in clinical trials. Health Technol Assess 1998, 2(14):i-iv. I-74

62. Boers M, Brooks P, Simon LS, Strand V, Tugwell P: OMERACT: an international initiative to improve outcome measurement in rheumatology. Clin Exp Rheumatol 2005, 23(5 Suppl 39):SI0-3. 
63. Pham T, Heijde D Van Der, Lassere M, Altman RD, Anderson J], Bellamy N, Hochberg M, Simon L, Strand V, Woodworth T, Dougados M: OMERACT-OARSI. Outcome variables for osteoarthritis clinical trials: The OMERACT-OARSI set of responder criteria. J Rheumatol 2003, 30(7): 1648-54.

64. Gossec L, Hawker G, Davis AM, Maillefert JF, Lohmander LS, Altman R, Cibere J, Conaghan PG, Hochberg MC, Jordan JM, Katz JN, March L, Mahomed N, Pavelka K, Roos EM, Suarez-Almazor ME, Zanoli G, Dougados M: OMERACT/OARSI initiative to define states of severity and indication for joint replacement in hip and knee osteoarthritis. J Rheumatol 2007, 34(6): I432-5.

65. Deyo RA, Battie M, Beurskens A), Bombardier C, Croft P, Koes B, Malmivaara A, Roland M, Von Korff M, Waddell G: Outcome measures for low back pain research. A proposal for standardized use. Spine 1998, 23( I8):2003-13.

66. Rebbeck TJ, Refshauge KM, Maher CG, Stewart M: Evaluation of the core outcome measure in whiplash. Spine 2007, 32(6):696-702.

67. Paterson C: Measuring outcomes in primary care: a patient generated measure, MYMOP, compared with the SF36 health survey. $B M]$ 1996, 312:1016-20.

68. Mullis R, Barber J, Lewis M, Hay E: The ICF Core Sets for low back pain: Do they include what matters to patients? I Rehab Med 2007, 39(5):353-7.

69. Woolf SH: The meaning of translational research and why it matters. JAMA 2008, 299(2):2II-3.

\section{Pre-publication history}

The pre-publication history for this paper can be accessed here:

http://www.biomedcentral.com/1471-2474/10/3/prepub

Publish with Bio Med Central and every scientist can read your work free of charge

"BioMed Central will be the most significant development for disseminating the results of biomedical research in our lifetime. "

Sir Paul Nurse, Cancer Research UK

Your research papers will be:

- available free of charge to the entire biomedical community

- peer reviewed and published immediately upon acceptance

- cited in PubMed and archived on PubMed Central

- yours - you keep the copyright 